\title{
MEASURING THE PERFORMANCE OF CHILE'S TAX ADMINISTRATION*
}

\author{
Pablo Serra* $^{* *}$
}

\begin{abstract}
This purpose of this article is to develop an effectiveness indicator (EI) for Chile's tax administration. We assume that the goal of the Chilean Internal Revenue Service (SII) is to maximize tax revenue while minimizing compliance costs. Sample taxpayer surveys and statistical information both show that SII service standards - a proxy for compliance costs improved in the 1990s. Compliance rates, which are used as EI by the SII itself, also improved significantly. Regression analysis, however, suggests that this improvement can largely be explained by the strong economic growth experienced during the period. We argue that an appropriate EIfor the goal of revenue maximization is the actual compliance rate divided by maximum achievable compliance given the values of variables that are beyond SII control.
\end{abstract}

Keywords: Tax administration, performance indicators, Chile

JEL Classification: D73, H26.

* This research was funded by FONDECYT (Project N¹960730). The author gratefully acknowledges two anonymous referees for very detailed comments and helpful suggestions. Paulo Henríquez provided excellent research assistance.

** Centro de Economía Aplicada, Universidad de Chile, República 701, Santiago, CHILE. 


\section{Introduction}

This paper develops performance indicators for Chile's tax administration (TA). Although the President himself appoints the director of the Chilean Internal Revenue Service (SII), this is an autonomous decentralized public agency. The government decides the tax structure and sets the SII budget, while the latter formulates and executes tax enforcement strategy. ${ }^{1}$ The tax authority therefore has to deal with two problems, namely setting tax administration performance goals, and devising suitable incentives for TA to respond to them (Slemrod and Yitzhaki 1996). This article focuses on the first one.

Since 1990, Chilean governments have been consistently placing greater emphasis on the performance of public bodies. The initial steps in this process involved strategic planning exercises with a view to defining mission statements in the different public agencies; these were followed by pilot projects to devise performance targets. In 1994 the process gathered pace, and 26 public bodies, including the SII, had defined performance targets within a year. By 1997 the number had grown to 67, covering $80 \%$ of all State agencies. Moreover, since 1998, qualified public-sector employees have been receiving bonuses based on achievement of their agencies' goals.

The bonuses earned by SII staff depend on the tax revenue collection. The benchmark is set equal to revenue collected during the previous year, increased by the rate of growth of GDP times 1.1 (the estimated elasticity of tax revenue collection with respect of GDP). The maximum bonus varies between $13.5 \%$ and $27 \%$ of salary depending on the position of the staff member concerned. If revenue collected exceeds by less than $0.86 \%$ the benchmark, they do not receive the bonus. When it exceeds by more than $2.4 \%$ the benchmark, staffs earn $100 \%$ of their maximum payable bonuses. In between $0.86 \%$ and $2.4 \%$ they receive increasing percentages of

1 Melumad and Mokherjee (1989) speculate that elected authorities tend to shift unpleasant tasks, such as tax enforcement, on to relatively autonomous agencies. Cremer el al. (1990) claim that a two-tier decision-making procedure is quite typical in this setting in real life. In fact, it has been institutionalized in countries as diverse as Kenya and the USA. 
the maximum bonus. Apart from this, each year the best appraised third of the staff receive a bonus equal to $4 \%$ of salary, with the next third obtaining $2 \%^{2}$

This new emphasis on productivity is part of an international trend in public administration aimed at fostering a high-performance culture in less centralized public sectors. The first experience of this was the British public-sector reform that began in 1982, which was closely followed by New Zealand and Australia. Underlying this development is the concept of performance measurement, combined with incentive schemes to encourage efficiency. Governments to set targets for subordinate agencies or to specify required levels of service in a service contract use performance indicators (PIs). PIs are also an effective internal management tool, as they provide a sound basis for appraising programs and organizational units (Baker 1994).

The literature distinguishes three categories of performance indicators measuring economy, productivity (or efficiency), and effectiveness. Economy indicators measure the ability to carry out tasks at minimum cost. An example would be total TA expenditure per taxpayer. Efficiency or productivity indicators measure the relationship between outputs and inputs, for example the number of audits carried out per tax auditor. Lastly, effectiveness indicators (EIs) measure the degree of fulfillment of institutional objectives; the latter usually include user or citizen satisfaction, but as this is hard to integrate into a common indicator, it is normally assessed separately.

TAs mostly use productivity indicators. Although these are quite useful as internal management tools, they can lead to misleading conclusions if mistaken for indicators of effectiveness. The simplest productivity indicator in the TA field is the quotient between the total amount collected and the cost of administrating the tax system. However, this indicator would show an improvement if tax revenue collection were to rise as a result of higher tax rates, even if TA efforts had not increased. Another productivity indicator is the yield of additional resources allocated to TA. However, as the marginal productivity of tax enforcement is likely to be decreasing (Poterba, 1987), an increase in the TA budget would lower the indicator, even if TA performance

2 Since the 1970s, SII employees have received a bonus of $18 \%$ of their salaries when the growth of revenue collection exceeds that of GDP by at least one percent. In practice this means they receive the bonus every year when the economy grows. 
were to remain unchanged. ${ }^{3}$

The number of taxpayers penalized, or the amount collected from fines, are also often proposed as possible performance indicators. Cremer et al. (1990) suggest maximizing the number or amount of fines for a given audit budget, as a possible TA goal. Hunter and Nelson (1996) assume the output of TA to be tax enforcement, and that this can be adequately measured by the additional taxes and penalties assessed by the TA. One target used by the SII in Chile are revised penalty appraisals, i.e. final penalty assessments following appeals and revision by SII regional directors. However, these could also be misleading indicators. When tax enforcement effort increases, taxpayers are likely to respond by reducing evasion. On the other hand, the proportion of evasion detected can be expected to increase, so the effect on revenue collected from fines is ambiguous as a measure of greater TA efficacy.

The objectives assigned to any given TA will determine the precise form of its effectiveness indicators. Maximization of tax revenue is an appropriate TA goal, but it needs to be complemented by minimization of compliance costs - i.e. the costs citizens face in complying with the tax laws. Otherwise, high compliance costs could cause significant welfare losses. Unfortunately, there are no estimates of compliance costs for Chile, but empirical evidence from other countries suggests they may be substantial. Blumenthal and Slemrod (1992) estimate that compliance costs in the US approach $7 \%$ of personal income tax revenues, and over $3 \%$ of corporate tax revenues (Slemrod and Blumenthal, 1995). This work considers the two objectives of maximizing revenue and minimizing compliance costs separately, mainly because series for the latter are not available.

For the revenue maximization goal, tax revenue itself could serve as the EI. However, this would fail to take account of the fact that the tax base may change as the tax structure varies and, or, more often, as a result of fluctuations in the economy. Accordingly, a better EI is the compliance

3 The Inter-American Tax Administrators Center estimates the quotient between revenue collection and the tax administration budget for countries in the region. The SII website also provides comparative data, and the IRS in the United States publishes its own quotient. Agha and Haughton (1996), using data from 17 OECD countries for 1987, found that an extra dollar spent on TA raised revenue by US\$12. A study commissioned by the SII in Chile estimated that $\$ 1$ of additional enforcement spending increased VAT revenue by $\$ 31$ (Engel et al., 1999). 
rate. The IMF has used the VAT compliance rate as an effectiveness measure in many countries, along with a National Accounts-based methodology for calculating it. Some international comparisons have also been performed, with Silvani and Brondolo (1993) computing the 1991 compliance rate for 20 countries. Since calculating the potential tax base requires information that might not be available in all countries, the IMF also uses the productivity rate, i.e. the ratio between VAT revenue collected, as percentage of GDP, and the tax rate, as a rule of thumb. This indicator is equal to the tax compliance rate times the breadth of the tax base (i.e. the VAT base as a percentage of GDP). ${ }^{4}$

The compliance rate is also affected by variables beyond TA control, such as the tax rate. Theoretically an appropriate EI would be the ratio between the actual compliance rate and the maximum compliance that could possibly be achieved, given the value of variables affecting tax compliance which are beyond TA control. In this note we use that ratio to estimate TA effectiveness. Two different techniques are used to estimate maximum feasible compliance: the Stochastic Production Frontier Model developed by Aigner, Lovell and Schmidt (1977) and Data Envelopment Analysis (DEA), proposed by Charnes, Cooper and Rhodes (1978, 1981).

The other TA goal should be to minimize compliance costs, and in this case the most appropriate EI would be the minimum compliance cost that can be achieved, divided by the actual compliance cost. Measuring compliance cost is not a simple task, however, and there are only a few studies that estimate it $;^{5}$ estimating minimum compliance cost is even harder. Indirect approaches can be used, however, such as measuring taxpayer satisfaction with services provided by the TA expressed through sample taxpayer surveys. Revenue Canada is developing client service standards for all its major programs, and relies heavily on client consultation to define the important service elements and expectations about service delivery (Baker, 1994).

Measuring taxpayer satisfaction has two advantages over the use of un-normalized compliance costs. Firstly, it is more effective in isolating the evaluation of TA from aspects that

4 According to their estimates, Chile's 74\% compliance rate ranks eighth in the sample (the average is $69.2 \%$ ), and its productivity level of 0.44 puts the country in sixth place.

5 Pitt and Slemrod (1987) estimate compliance costs by observing those taxpayers who would save money by itemizing but who choose not to do so and Seltzer (1997) undertakes a case study. Most other studies rely on 
affect compliance costs but are not under its control, such as the complexity of the tax structure and the quality of tax legislation (though the latter can be enhanced by rulings and other technical information prepared by the TA). Secondly, like any other good or service, its valuation by consumers is highly relevant. The TA should then measure the quality of services provided to taxpayers, considering the attributes most valued by them. However, results from sample taxpayer surveys need to be complemented with more objective data, mainly for internal use, as people's perceptions are not necessarily based on their experience.

The SII in Chile uses compliance rates and taxpayer service standards as EIs (see, for instance, the reports, Resultados de una Gestión and Informe de Autoevaluacion Tecnica, posted on the SII website). Service quality is mostly measured through taxpayer surveys, although more recently this method has been backed up by a statistical analysis of quality standard measurements. The SII also publishes estimates of compliance in both VAT and company taxation. Both indicators displayed significant improvements during the 1990s. The regression results reported in this paper, however, show that this improvement can largely be explained by the sustained economic growth experienced during the period. The compliance rate divided by the maximum compliance achievable displays smaller gains in the 1990s.

The remainder of this paper is organized as follows: section 2 analyzes the definition of TA objectives, while section 3 develops performance indicators for TA. Section 4 uses these to measure the performance of the Chilean TA. Section 5 focuses on evolution of taxpayer services. The final section offers some conclusions.

taxpayer surveys. 


\section{The objective of tax administration}

Prior to developing any effectiveness indicator, tax administration goals need to be defined. The public finance literature generally assumes that the government's aim when formulating tax policy is to maximize social welfare. This is achieved when the marginal benefit of government expenditures is equal to the marginal cost of collecting taxes, plus the marginal utility of income of the representative taxpayer (Kaplow, 1990; Mayshar, 1991). Thus, maximization of societal welfare implies minimization of collection costs. Since the TA is in charge of designing and implementing the enforcement strategy, the TA objective should be to minimize collection costs. In this section we postulate that joint minimization of tax evasion and compliance costs serves as a proxy for minimizing collection costs.

The literature distinguishes six components of collection costs (Slemrod and Yitzhaki 1996): the deadweight loss - inefficiency arising from substitution by taxpayers from taxed to untaxed, or less taxed activities; the compliance cost; the administrative cost - i.e. the TA budget; the cost of non-compliance - the cost of concealing income from TA; the excess burden of tax evasion - the risk borne by taxpayers who evade; and the costs arising from the market malfunctioning that results from the unfair competition that non-evaders face from evaders (Tanzi and Shome 1993). In what follows, we show that collection costs generally fall when greater TA effort results in a higher compliance rate.

A higher compliance rate enables the government to collect the same revenue with either lower tax rates and/or a reduced TA budget. The optimal response is likely to consist of a combination of the two, but for simplicity we assume the government always reacts to a higherthan-expected compliance rate by lowering the TA budget, thereby leading to lower administrative costs. With compliance restored to its initial level, we assume that the excess burden of tax evasion remains unchanged. In order to analyze how those changes affect the other collection costs, it is helpful to describe the mechanism through which higher compliance is achieved. 
Firstly, we assume that the increase in compliance is due to a higher probability of detection (for empirical evidence, see Alm, McClelland and Schulz, 1992; Dubin, Graetz and Wilde, 1990; and Robben et al., 1990). The reduction in the TA budget takes the probability of detection back to its original level. If an increase in the audit rate is what explains the higher likelihood of detection, the budget cut completely restores the initial situation, with the only gain being the reduction in administrative expenses. A different case occurs when better information allows the TA to detect more evasion with the same number of audits. In this case, the budget cut reduces the number of audits, thereby lowering the compliance cost; but, on the other hand, if taxpayers have to provide the additional data used to improve detection, overall compliance costs could increase.

A higher compliance rate could be also explained by a shrewder selection of taxpayers for audit. The literature reports on how the use of data and statistical techniques to select audits improves compliance (Hunter and Nelson, 1996, and Baker, 1994). ${ }^{6}$ Improving the selection of taxpayers for audit provides benefits in addition to collecting the same amount with lower administrative costs. It reduces the dispersion in the effective tax rate by focusing audit efforts on individuals considered most likely to evade. The latter will react to an increase in the audit rate by reducing their evasion, thereby increasing their effective tax rate. By similar reasoning, the effective tax rate among taxpayers with a lower probability of evading is likely to decrease. Since there is theoretical evidence showing that the distortion caused by taxes rises more than proportionally with tax rates, reducing dispersion decreases the dead-weight loss of taxation even if the mean remains unchanged. Less dispersion in the effective tax rate also lowers the costs arising from the market malfunctioning that results from the unfair competition that non-evaders face from evaders

Higher compliance can also be explained by a rise in non-compliance costs. For instance, computerized matching of third party data could raise the cost of concealing income. For simplicity, assume a rise in unit non-compliance costs. Eventually, once the government has

6 IRS random auditing of the federal personal income tax in the US yields US \$ 289 on average, while those conducted using a discriminant function on average yield US \$5,500. 
lowered the TA budget to the point where the compliance rate falls back at its initial level, the total non-compliance cost would be higher since the unit non-compliance cost has increased. The increase in non-compliance costs would not necessarily outweigh the decrease in the administrative cost. Moreover, in the societal welfare function non-compliance costs would probably weigh less than administrative costs.

The tax administration can also increase compliance by being more responsive to taxpayers' needs. There is empirical evidence that tax compliance reflects not only enforcement, but also efforts to increase taxpayers' moral inhibitions about evading. The TA fosters compliance by being congenial towards taxpayers, by providing timely information and simplifying tax declaration procedures, as well as by informing citizens about the use of tax revenues when these are spent in ways consistent with the ir preferences (Thurman, 1991; and Thurman, St. John and Riggs, 1984). Based on an analysis of responses to a questionnaire mailed to Australian taxpayers, Wallschutzky (1984) suggests that taxpayer satisfaction with the way they are treated in their dealings with the TA may also be a significant influence on future levels of tax evasion.

When TA efforts to meet taxpayers' needs provoke higher compliance, these efforts also reduce compliance costs. If a budget cut lowers the quality of service to its initial level, then the only gain is the reduction in administrative costs. The TA could decide, however, to maintain the standard of service but reduce its tax enforcement effort by cutting the number of audits. In this case administrative and compliance costs will both fall. Of course, tax compliance is not necessarily the same in both cases, so a direct comparison between the two responses would be inappropriate.

To summarize the discussion so far, collection costs are likely to be positively related to tax compliance. The relationship, however, depends on the way compliance maximization is achieved - in particular; on how the TA allocates its budget between tax enforcement activities and improving the quality of taxpayer services. If the only target set for the TA is to maximize tax compliance, it will allocate its budget such that the last dollar spent on enforcement activities produces the same tax revenue as the last dollar spent on improving taxpayer services. But the last dollar spent on improving services will have the additional benefit of also lowering compliance costs. Hence, unconditional maximization of compliance is unlikely to minimize 
collection costs, and the additional goal of minimizing compliance costs needs to be imposed explicitly. 


\section{Performance indicators for revenue maximization}

Having set the goals for the tax administration, we turn to the development of effectiveness indicators. We focus firstly on the TA objective of maximizing compliance for a given budget. The higher the compliance rate, holding all other variables constant, the greater effectiveness will be. The compliance rate, however, does not allow us to make inter-period comparisons, for tax compliance depends on many other variables besides the performance of the tax administration. The appropriate performance indicator is therefore:

$$
\alpha=\frac{s}{s^{*}}
$$

where $\alpha$ is the TA effectiveness indicator, $\mathrm{s}$ the compliance rate, and $\mathrm{s}^{*}$ the maximum compliance that can be possibly achieved.

The traditional economic theory of evasion, pioneered by Allingham and Sandmo (1972), assumes that each taxpayer makes a portfolio choice between a risk-free asset (declared income) and a risky asset (undeclared income). Their model makes the compliance rate a function of the probability, $\mathrm{p}$, of evasion being detected, the size of the penalty, $\mathrm{m}$, the level of income, $y$, and the tax rate, $\mathrm{t}$, as summarized in the following expression:

$$
\mathrm{s}=\mathrm{f}(\mathrm{y}, \mathrm{t}, \mathrm{m}, \mathrm{p})
$$

In what follows we omit the unit penalty, as both theory and the evidence are ambiguous about its effect on revenue collected (see for instance, Besley and McLaren, 1993; and Pommerehne and Weck-Hannemann, 1996). The perceived probability of detection is also difficult to measure, so many empirical papers resort to the following alternative:

$$
s=f(B, t, g, \alpha)
$$


where $\mathrm{B}$ denotes the tax base, and $\mathrm{g}$ the quotient between the TA budget and the tax base (when the government allocates resources directly to different TA items, $\mathrm{g}$ becomes a vector). This formula is more general, since $\alpha$ also includes positive encouragement of compliance by TA.

When there is a long time series, the aggregate compliance function can be estimated econometrically. Assuming a linear specification for (3) we write:

$$
s=c_{0}+c_{B} B+c_{t} t+c_{g} g+c_{\alpha} \alpha+v
$$

where $\mathrm{v}$ is the error term. Effectiveness, $\alpha$, is not observable, so the residuals can be interpreted as an effectiveness indicator. When $\alpha$ is not correlated with the other variables, its omission does not bias the estimation, but it could make it highly inefficient.

More efficient estimates can be obtained using the sochastic production frontier method developed by Aigner, Lovell and Schmidt (1977). This involves specifying an error term consisting of two components, one normal and the other taken from a one-sided distribution The corresponding equation for estimation is:

$$
\mathrm{s}=\mathrm{c}_{0}+\mathrm{c}_{\mathrm{B}} \mathrm{B}+\mathrm{c}_{\mathrm{t}} \mathrm{t}+\mathrm{c}_{\mathrm{g}} \mathrm{g}+\mathrm{v}-\mathrm{u}
$$

where $\mathrm{v}$ is a normal error term representing pure randomness and $\mathrm{u}$ is a non-negative error term representing technical inefficiency. Aigner, Lovell and Schmidt (1977) point out that all coefficients except $\mathrm{c}_{0}$ can be estimated in an unbiased and consistent fashion using least squares.

Data envelopment analysis (DEA), proposed by Charnes, Cooper and Rhodes (1978, 1981), offers an alternative approach for estimating performance. The performance indicator is calculated as the ratio between a weighed sum of outputs and a weighed sum of inputs. Performance in any given year would be considered efficient if there is no other year, or linear combination of years, that produces more of each output for a given level of inputs. The main advantages of DEA are that 
it allows multiple outputs to be considered - for instance tax compliance and taxpayer satisfaction in a single indicator, and neither the production function nor the distribution of error terms needs to be specified. This deterministic approach has its disadvantages, however. Estimations lack statistical properties, thus rendering hypothesis testing impossible. Moreover, by ignoring the possibility that a given performance year could be affected by factors beyond TA control, DEA results become highly sensitive to the presence of outliers. Another drawback of DEA analysis is that it uses a subset of the available data in each estimation.

One of the channels through which TA raises compliance is by increasing the chances of tax evaders being detected. Accordingly, the additional taxes and fines assessed or levied by the TA can be used to build an EI for this specific activity. However, as mentioned before, penalty collection is not an appropriate indicator in itself. The appropriate performance indicator is the percentage of total tax evasion that is caught by the TA; i.e. the quotient between fines levied and total estimated tax evasion. This is still an incomplete indicator, however, as it fails to consider resources devoted to this activity; nonetheless, it does at least provide an idea of how tax-evasion detection is performing. 


\section{Results}

In this section we apply the effectiveness indicator, s/s*, to VAT in Chile. Focusing on VAT is justified on several grounds: firstly, it accounts for about $45 \%$ of all tax revenue collected; secondly, there is longer series of compliance estimates for VAT. Moreover, VAT evasion reduces the tax base in other tax categories, with about $75 \%$ of company income tax evasion explained by evasion of VAT. Given that personal and company income taxes are integrated, VAT evasion also leads to evasion of personal income tax .

VAT is charged at a flat rate of $18 \%$, except for exports, which are zero-rated. Construction companies receive a credit equivalent to $65 \%$ of the debit generated by the sale of residential buildings, whereby it is estimated that the effective VAT rate on house building is zero. Sales of certain goods and services are exempt from paying VAT (in which case the vendors cannot recover the VAT paid on their purchases). The main goods and services exempt from paying VAT are passenger transport, life insurance, healthcare (partially), education and financial interest.

The VAT compliance rate is available for the period 1981-1998. The Internal Revenue Service (SII) estimates this by calculating potential revenue based on the National Accounts for each year and comparing this with the revenue actually collected. Broadly speaking, the VAT base is calculated by adding together the different transactions that are subject to VAT. The main component is final consumption, both public and private, of goods and services that are subject to the tax. Apart from this, there is the purchase of intermediate and investment goods subject to VAT, which are then used in the production of goods and services that are exempt.

Maximum compliance, $\mathrm{s}^{*}$, was first estimated using the stochastic frontier approach. Since the tax rate did not vary much during the period, equation (5) was simplified to:

$$
\mathrm{s}=\mathrm{c}_{\mathrm{tB}} \mathrm{tB}+\mathrm{c}_{\mathrm{g}} \mathrm{g}+\mathrm{v}-\mathrm{u}
$$


The tax base is measured in thousand billion pesos at January 1997 prices, with $g$ denoting the number of employees per thousand billion pesos of revenue collected. The number of employees corresponds to the entire TA; hence we are implicitly assuming that the internal allocation of resources did not change much between 1981 and 1998. In this period the tax base almost doubled in real terms, and the number of employees also grew, but more slowly; as a result, the number of employees of per unit of revenue collected declined. The resources allocated to tax administration, along with the tax rate, the tax base and the tax revenue collection are all shown in Table 1.

Table 1: SII budget and employees, tax rate, tax base, and revenue collected

\begin{tabular}{ccc|ccc}
\hline Year & Tax Rate & SII employees & $\begin{array}{c}\text { SII } \\
\text { Budget }\end{array}$ & Tax Base & $\begin{array}{c}\text { Gross } \\
\text { Collection }\end{array}$ \\
\hline & \% & & Ch\$ thousand billion at January 1997 prices \\
\hline 1980 & 20 & & & $8,956,438.8$ & $1,725,348.0$ \\
1981 & 20 & 1,863 & $17,494.8$ & $9,245,481.5$ & $1,723,637.0$ \\
1982 & 20 & 1,828 & $16,956.6$ & $8,164,361.5$ & $1,245,324.9$ \\
1983 & 20 & 2,025 & $12,457.7$ & $7,833,715.5$ & $1,435,083.4$ \\
1984 & 20 & 1,936 & $12,821.3$ & $8,000,241.1$ & $1,492,672.6$ \\
1985 & 20 & 2,028 & $12,318.4$ & $8,410,264.1$ & $1,633,045.2$ \\
1986 & 20 & 2,050 & $12,732.0$ & $8,603,106.1$ & $1,746,536.7$ \\
1987 & 20 & 1,999 & $14,334.1$ & $9,533,286.5$ & $1,891,444.0$ \\
1988 & 18 & 1,979 & $15,250.5$ & $10,685,783.7$ & $1,935,155.0$ \\
1989 & 16 & $2, .185$ & $14,369.4$ & $12,059,344.4$ & $2,026,208.9$ \\
1990 & 17 & 2,198 & $13,689.9$ & $12,118,501.9$ & $2,253,722.7$ \\
1991 & 18 & 2,209 & $13,268.1$ & $13,177,518.5$ & $2,529,228.7$ \\
1992 & 18 & 2,437 & $17,297.4$ & $14,794,648.7$ & $2,789,254.5$ \\
1993 & 18 & 2,405 & $18,364.0$ & $15,667,875.5$ & $3,120,096.5$ \\
1994 & 18 & 2,624 & $20,389.3$ & $16,399,048.0$ & $3,217,856.1$ \\
1995 & 18 & 2,624 & $24,195.3$ & $17,730,197.7$ & $3,531,201.4$ \\
1996 & 18 & 2,632 & $26,872.1$ & $18,713,378.3$ & $3,702,833.1$ \\
1997 & 18 & 2,622 & $29,412.2$ & $19,786,277.5$ & $3,950,976.7$ \\
1998 & 18 & 2,679 & $31,580.7$ & $20,481,699.0$ & $4,015,598.8$ \\
\hline & & & & & \\
\hline
\end{tabular}




\section{Source: SII}

The stochastic frontier was estimated using the maximum likelihood method. The distribution of the error term is assumed to be normal, and the term representing technical inefficiency is assumed to have a truncated normal distribution. The results of the regression were as follows: ${ }^{7}$

$$
\ln \mathrm{s}=0.411 \ln (\mathrm{tB})+0.353 \ln \mathrm{g}
$$

The log-likelihood estimator is 35, and t-statistics are shown in brackets. The variance of the normal error term, v, is 0.00089 , and the variance of the non-negative error term, $\mathrm{u}$, representing technical inefficiency, is 0.00087 . Thus the quotient, $\mathrm{u} / \mathrm{v}$, is 0.99 , and the t-statistic is 0.386 , which indicates that estimated inefficiency is not significant. This is reflected in effectiveness indicators with small fluctuations. The reason for this is that the same agency is being analyzed over several years, so wide variations in its effectiveness cannot be expected. As inefficiency is measured in terms of the best performance years in the series, this is not very significant for any observation.

According to the regression results, compliance improves strongly with potential VAT collection: a $10 \%$ increase in the latter raises the former by $4.1 \%$, which gives an elasticity of revenue collected with respect to hypothetical collection of 1.45 . This elasticity is quite high compared to its usual range of 1.1 to 1.2. The high responsiveness of tax compliance to the tax base could be explained by the existence of scale economies in tax enforcement, taxpayers higher willingness to pay taxes in a fast-growing economy, and changes in the tax structure. There is less room for evasion in imports than in domestic activities, so it is easier to achieve a high VAT compliance rate in an economy with high foreign trade indices. Following a sharp decline in 1982,

7 The OLS regression run for years 1981 through 1998 gives the following results:

$\ln \mathrm{s}=0.409 \ln (\mathrm{tB})+0.347 \ln \mathrm{g}$

The t-student statistics are 169 and 9, respectively. The R-squared is 0.67 , log-likelihood statistic is 34.9 , and the Durbin-Watson statistic is 2.14 . 
imports grew faster than the tax base in the 1980s in Chile, whereas the two increased more or less at the same pace during the 1990s. The share of imports in the economy actually declined in 1998. Unfortunately, imports could not be incorporated as an independent variable in the regressions, however, because they are highly correlated with the tax base.

The effectiveness indicator, $\mathrm{s}_{\mathrm{s}} \mathrm{s}^{*}$, is shown in the second column of Table 2 , where $\mathrm{s}^{*}$ is the exponential of the efficient value of $\log g$ determined by the regression. This suffered a setback in 1982, when the country passed through a severe crisis in which GDP shrank by approximately $14 \%$. It might be conjectured that in crisis periods voluntary taxpayer compliance by taxpayer would decrease. The indicator recovered in 1983, and fluctuated over the rest of the decade, ending at a relatively low level in 1990. It recovered in 1991 and continued to rise through 1992, before peaking in the following year. The indicator settled at a slightly lower level in 1994-97 before declining further in 1998. The figure for that year is provisional, however, as the corresponding National Accounts are still being revised.

In 1990 a new tax administration introduced several new programs aimed at improving enforcement and to raising taxpayers' willingness to pay, and this would explain the rise in the EI in the early 1990s. The measures included withholding at source in activities with high VAT evasion rates, and a strengthening of existing enforcement programs. Services provided to taxpayers were also improved, as discussed below, and so was the indicator used to measure tax inspector performance. What, therefore, explains the ensuing decline in performance? One possibility is the TA's strong focus on taxpayer satisfaction. The auditors' association has claimed that the short time they have for approving taxpayers' requests sometimes prevents a thorough examination of documents.

Part of the change in the performance indicator can also be attributed to variables not included in the regression. In December 1989 a center-left government was elected, with a new president taking office in March 1990. A majority of income earners - responsible for most VAT payments - strongly disliked the new government and firmly believed that it would jeopardize the country's flourishing economy. At this time, voluntary taxpayer compliance, which was also negatively affected by the 1990 tax rate hike, declined. Part of the explanation of the strong recovery in compliance that occurred in 1992 is that taxpayers' fears of a economic decline did not 
materialize. On the contrary, the economy grew at an average annual rate of 6.5 percent between 1989 and 1996, the fastest growth period in the country's history. On the other hand, following a political truce that that lasted from 1990 to 1994 after the restoration of democracy, opposition members of parliament have since become more outspoken in their criticism of government mismanagement and corruption. This could help explain the compliance decline in the mid 90s.

Performance indicators were also computed using data envelopment analysis (DEA), producing the results shown in the third column of Table 2 . These do not differ greatly from those calculated using the stochastic frontier method, except for the last three years. In fact, the correlation coefficients between the two indicators are $0.65,0.80$ when 1998 is excluded, and 0.84 when the last three years are omitted. A possible explanation for the divergence between the two indicators in the last three years is that the model specification for the stochastic frontier has recently become less appropriate. In particular, the results of that model suggest that compliance rises strongly with the tax base, but this has a limit. The two performance indicators are shown in Graph 1.

What difference does it make if the compliance rate is used as a measure of effectiveness instead of the indicators proposed? The correlation coefficient between the EIs and the compliance rate is lower than the correlation between the PIs estimated using the stochastic frontier and DEA analysis, respectively. The correlation of the indicator $\mathrm{s} / \mathrm{s}^{*}$ with the compliance rate is 0.59 when $\mathrm{s}^{*}$ is computed using the stochastic frontier method, and 0.67 when DEA is used. When the three final observations are eliminated, the coefficients are 0.62 and 0.74 respectively. The compliance rate fluctuates more sharply than the EIs over time. This is a plausible result considering that the regression in the stochastic frontier approach and the mathematical programming of DEA analysis both attempt to fit the model to the actual data. The compliance rate rises sharply in the early 1990s, but the EIs do not. 
Table 2: Effectiveness Indicators

\begin{tabular}{lccl}
\hline Year & COMPLIANCE & SPF & DEA \\
\hline 1981 & 0.766 & 0.990 & 1.000 \\
1982 & 0.642 & 0.946 & 0.969 \\
1983 & 0.716 & 0.975 & 0.997 \\
1984 & 0.734 & 0.984 & 1.000 \\
1985 & 0.730 & 0.979 & 0.994 \\
1986 & 0.745 & 0.982 & 0.997 \\
1987 & 0.712 & 0.971 & 0.979 \\
1988 & 0.693 & 0.975 & 0.981 \\
1989 & 0.710 & 0.982 & 0.988 \\
1990 & 0.704 & 0.974 & 0.980 \\
1991 & 0.732 & 0.976 & 0.983 \\
1992 & 0.771 & 0.979 & 0.986 \\
1993 & 0.817 & 0.989 & 1.000 \\
1994 & 0.804 & 0.981 & 0.988 \\
1995 & 0.797 & 0.978 & 0.990 \\
1996 & 0.800 & 0.978 & 0.994 \\
1997 & 0.803 & 0.978 & 1.000 \\
1998 & 0.775 & 0.964 & 1.000 \\
\hline & & &
\end{tabular}

Lastly, Table 3 shows the performance indicator for detection of VAT evasion, which is calculated as the quotient between fines collected and total estimated evasion. This indicator posted a strong gain in 1992, which has been followed by mild fluctuations since 1993. Penalty collection increased by about $50 \%$ in 1992 , as the result of a policy change implemented in that year. Prior to 1991, the performance of the SII regional offices was rated by the level of their penalty assessments. From 1992 onwards, performance has been measured through net penalty appraisals, i.e. final assessments after elimination or reduction by the SII regional director. Penalty assessments by auditors fell dramatically in 1992, whereas fine collection increased. The possibility of a detected evader actually being penalized depends, among other things, on the efforts made by the TA to 
punish offenders. Consequently, fines actually collected are more suitable as an EI for TA enforcement efforts. ${ }^{8}$

This provides a vivid example of the potential of performance indicators to distort organizational behavior. In Chile, the evaluation of tax auditors by the level of fines assessed led to a large number of frivolous assessments, but this encouraged the tax inspectors to make frivolous estimates, probably causing significant costs (and great annoyance) to taxpayers. The implementation of performance indicators needs to be preceded by a thorough analysis of their implications for the behavior of the agency concerned. Otherwise, officials will try to maximize their score on the relevant PIs instead of fulfilling institutional objectives.

\section{Table 3: Chile: Vat Enforcement Efficiency}

(millions of Chilean pesos, constant January 1999 prices)

\begin{tabular}{|l|c|c|c|c|c|c|c|c|}
\hline & 1991 & 1992 & 1993 & 1994 & 1995 & 1996 & $1997^{\mathrm{a}}$ & $1998^{\mathrm{a}}$ \\
\hline VAT Sanction Collection & 7,640 & 11,911 & 10,680 & 13,530 & 12,368 & 13,806 & $15,222^{\mathrm{b}}$ & $18,342^{\mathrm{b}}$ \\
VAT Auditors Assessment & 55,147 & 40,126 & 36,746 & 42,834 & 40,387 & 40,043 & 42,533 & 53,173 \\
VAT Penalty Collection & 13.9 & 29.7 & 29.1 & 31.6 & 30.6 & 34.5 & 35.8 & 34.5 \\
VAT non-compliance rate (\%) & 26.8 & 22.9 & 18.3 & 19.6 & 20.3 & 20.0 & 19.7 & 22.5 \\
VAT non-compliance amount & 636,360 & 610,531 & 515,143 & 577,182 & 646,982 & 673,272 & 701,591 & 829,166 \\
IND. 2 : fines levied as a \%of & 1.20 & 1.95 & 2.07 & 2.34 & 1.91 & 2.05 & 2.17 & 2.21 \\
VAT non-compliance amount & & & & & & & & \\
\hline
\end{tabular}

Source: Subdirección de Estudios, SII.

Notes: ${ }^{a}$ Provisional figures. ${ }^{b}$ As from 1997, the SII changed its methodology for measuring revenue collected as a result of inspection. The new methodology involves measurement by plans and programs rather than by individual taxes, as had been the case up to 1996. In estimating effective revenue collected from VAT in 1997 and 1998 , the percentage change in the plans and programs relating to VAT was applied to the revenue actually collected in 1996 as a result of inspection.

8 Actual payment of the penalty depends also on the provisions established by law to make it enforceable, as well as on the determination of the judiciary to penalize tax evasion - aspects that are beyond the TA's control. In addition, there are the evaders who escape detection, and others who can avail themselves of expert legal assistance to overturn any penalty in court. 


\section{Taxpayers services}

There is sufficient qualitative evidence to claim that compliance costs have fallen since 1990. In fact, since the beginning of the 1990s, the TA has increased its efforts to improve the quality of taxpayer services. The opening of 12 new offices in the 1990s made it easier for taxpayers to interact with the TA. Tax forms were redesigned so that they can be filled in using computer printers, and most transactions can now be performed via Internet. Procedures have been simplified and the quality of technical assistance provided has improved. The number of frivolous penalty assessments by tax auditors has also been cut back.

With the aim of improving service quality, the SII installed suggestion boxes in its offices to enable taxpayers to make observations and complaints; this can also be done through the SII Website. In addition it drew up procedures for solving taxpayers' complaints, and it developed a comprehensive tax information policy. A series of easy-to-understand publications have been prepared and distributed to provide guidance to taxpayers on the procedures to be followed, the documents they need to submit, and the requirements they have to comply with in the ir various dealings with the SII. The same information can also be obtained by telephone or through the SII website. The latter also allows individual taxpayers to obtain specific information on the status of their income tax returns.

Sample surveys carried out in the early 1990s by opinion research companies indicated that the worst rated aspects of TA were the time needed to carry out tax-related "procedures", and a perception of unequal treatment at SII offices. Accordingly, steps were taken to enhance transparency: For example, taxpayers are now attended at SII offices by order of arrival. The SII has also redesigned its procedures for dealing with the public, streamlining and simplifying them, and eliminating unnecessary requirements. For instance, the Taxpayer Life Cycle project, implemented in 1993, cut the number of visits to TA offices required of people starting up an activity, obtaining a tax identification number and stamping VAT invoices, from three to one, thereby decreasing total waiting time from three days to less than one hour, and cutting the number of forms to be filled out from four to one. 
The "Maximum Waiting Time" project guarantees taxpayers a maximum waiting period of 30 minutes, and has established a time of 30 minutes for all "life-cycle" procedures since mid-1997. If this time limit is exceeded, the SII has to take the relevant documents to the taxpayer's address. As from December 1997, specialized software has been used to carry out the relevant time measurements. When the taxpayers arrives at the SII office, they take a numbered ticket from an electronic dispenser, and a counter registers this when they start to be attended. In this way, the software records on-line the main variables involved in the attention process, such as the number of staff attending the public, the number of taxpayers attended by each staff member, and times of attention. This on-line information also enables area heads to make rapid decisions on when to open up extra service points or take other measures to speed up the attention process.

These changes led to a significant improvement in user assessments of Taxpayer Life Cycle procedures. Sample surveys of taxpayers carrying out these procedures were undertaken in 1996 and 1997, and the results showed that satisfaction with the procedure has increased significantly in recent years. For example, $72.0 \%$ of the sample in 1997 responded that the quality of the information provided by the TA was either very good or excellent, up from $65.8 \%$ in 1996 , while $74 \%$ of respondents rated equality of treatment as either very good or excellent, compared to $66.6 \%$ in 1996. Lastly, $65.2 \%$ percent claimed to be satisfied or very satisfied with the time spent in the procedure, up from $50.9 \%$ in 1996.

According to survey respondents, the average time per procedure was 27.8 minutes in 1997 , down from 41 minutes in 1996. In 1997, 71.3\% of sampled taxpayers completed the ir procedure in a single visit, compared to $64 \%$ in 1996 , and the average number of visits needed to complete the procedure was 1.6. Most importantly, the number of people spending over 30 minutes at the SII office declined substantially between 1996 and 1997, as shown in Table 4. The 1998 figures, which were obtained using software, are even more impressive. As can be seen in the table, a small number of taxpayers spent more than an hour in their visits to SII offices. 
Table 4: Time spent by taxpayers in procedures related to the Life Cycle.

\begin{tabular}{|c|c|c|c|c|}
\hline \multirow{2}{*}{ Time spent } & \multicolumn{2}{|c|}{ Document stamping } & \multicolumn{2}{c|}{$\begin{array}{c}\text { Initiation of activities and Taxpayer ID } \\
\text { (RUT) }\end{array}$} \\
\cline { 2 - 5 } & 1996 & 1997 & 1996 & 1997 \\
\hline Less than 16 minutes & 28.9 & 45.7 & 32.4 & 49.3 \\
\hline 20 to 29 minutes & 13.4 & 15.3 & 17.3 & 15.0 \\
\hline 30 to 60 minutes & 37.1 & 32.7 & 36.6 & 27.4 \\
\hline over 60 minutes & 20.9 & 6.1 & 13.6 & 7.3 \\
\hline
\end{tabular}

Changes in the annual income-tax declaration process have also been introduced. In $1992 \mathrm{a}$ new on-line control system for income-tax returns was inaugurated, which expedites the system for dealing with taxpayers who are summoned to SII offices to explain and correct errors detected on their income-tax returns (the number dealt with by the end of August each year rose from 35,000 in 1991 to 61,200 in 1993). Moreover, taxpayers nowadays usually solve their problems in a single visit, whereas prior to 1992 it was not uncommon to have to make a second and even a third appearance. The new control system also reduced the number of taxpayers who were called in but ended up not having to alter their declarations from 65\% in 1991 to just 28\% in 1993 (Fanta, 1994).

Opinion research companies conducted sample surveys of people summoned to the SII to clarify their income-tax returns in 1994 and again in 1997. In 1994, 60.4\% of the sample rated the service as either good or very good, and $65.6 \%$ of those who had also been called the previous year considered that the service had improved since that time. In the 1997 survey, the equivalent approval rates increased to $64.1 \%$ and $72.5 \%$, respectively. More importantly, the service attributes that were rated worst in the initial surveys had dramatically improved. By 1994, $36.8 \%$ of the sample was either satisfied or very satisfied with waiting time, and $34.0 \%$ of the sample gave this same rating to equality in treatment by SII employees. By 1998 these figures had risen to $63.9 \%$ and $74.9 \%$, respectively. 


\section{Final remarks}

The Chilean TA has been using tax compliance rates and taxpayer satisfaction with services as effectiveness indicators (EIs), with both showing quite significant improvements since 1990. Opinion poll companies have been hired to measure satisfaction with the Internal Revenue Service (SII) and have conducted sample taxpayer surveys. Results from surveys carried out in the early 1990s have been used to improve the aspects that were worst evaluated by taxpayers. Inter-office comparison of taxpayer opinion has also become a useful internal management tool, leading to a substantial improvement in respondents' rating of the SII in subsequent studies

The VAT compliance rate rose sharply in the early 1990s, a development that has been claimed by the SII as proof of a substantial increase in its effectiveness; nevertheless, we advise caution with regard to the unqualified use of the compliance rate as an EI. There are other variables, apart from TA performance, that can explain the increase in compliance; in particular, regression results show that compliance is positively correlated with the tax base. Hence, the

unprecedentedly high growth of the economy during the 1990s also helps to explain the higher compliance rate; accordingly, we recommend using tax compliance as an EI, but normalized to the maximum compliance than can be achieved.

A major problem with the EIs proposed in this paper is the availability of timely information. In particular, there is a delay in publishing the National Accounts figures used in calculating the compliance rate. It takes over six months even to obtain provisional figures, and these are later revised and sometimes altered substantially. Clearly, employee incentives cannot be linked to performance indicators such as these and although the SII uses compliance rates as EIs, employee incentives are linked to revenue collection Revenue figures can be used to measure TA performance, and the appropriate PIs can be used to calibrate tax revenue targets when available. Moreover, there is greater concern within the SII for increasing the amount and quality of tax statistics. One possibility would be to implement a program of intensive audits conducted on a stratified random sample of surveys. As a result, the availability of information for calculating the indicators should increase over time. 


\section{REFERENCES}

Agha, Ali and Jonathan Haughton, 1996, "Designing VAT Systems: Some Efficiency Considerations," Review of Economics and Statistics 78(2): 303-08.

Aigner, Dennis, C.A. Knox Lovell and Peter Schmidt, 1977, "Formulation and estimation of stochastic frontier production function models," Journal of Econometrics 6: 21-37.

Allingham, M.G., and A. Sandmo, 1972, "Income Tax Evasion: A theoretical Analysis", Journal of Public Economics, Vol 1 (3/4):323-38.

Alm, James, Gary H. McClelland and William D. Schultz, 1992, "Why do people pay taxes?", Journal of Public Economics 48: 21-38.

Baker, W.V., 1994, "Performance measurement in Taxation: the Revenue Canada Experience, Public Management, Occasional Papers No 5, OECD, ch.3.

Besley, Timothy and John McLaren, 1993, "Taxes and Bribery: The Role of Wage Incentives”, The Economic Journal 103: 119-141.

Blumenthal, Marsha and Joel Slemrod, 1992, "The compliance cost of the U.S. individual income tax system: A second look of tax reform," National Tax Journal 45, 185-202.

Charnes, A., W.W. Cooper and E. Rhodes, 1978, "Measuring the Efficiency of decision Making Units," European Journal of Operational Research 2(6): 429-444.

Cremer, H., M. Marchand and P. Pestieau, 1990, "Evading, Auditing and Taxing: The EquityComplianceTradeoff', Journal of Public Economics 43: 67-92.

Dubin, Jeffrey, Michael Graetz and Louis Wilde, 1990, “The Effect of Audit Rates on the Federal Individual Income Tax", National Tax Journal 43(4): 395-409. 
Engel, E, A. Galetovic and C. Raddatz, 1999, "A Note on Enforcement Spending and VAT Revenues," Working Paper 52, Serie Económica, Departamento de Ingeniería Industrial, University of Chile.

Fanta, Enrique, 1994, “Fiscalización Impuesto a la Renta," Masters Degree Thesis, University of Chile.

Hunter, William and Michael Nelson, 1996, “An IRS Production Function,” National Tax Journal XLIX (1): 105-115.

Kaplow, Louis, 1990, "Optimal taxation with costly enforcement and evasion", Journal of Public Economics 43: 221-236.

Mayshar, Joram, 1991, “Taxation with Costly Administration," Scandinavian Journal of Economics 93(1), 75-88, 1991.

Pitt, Mark and Joel Slemrod, 1989, "The Compliance Cost of Itemizing Deductions: Evidence from Individual Tax Returns," American Economic Review 79(5): 1224-32.

Pommerehne, Werner and Hannelore Weck-Hannemann, 1996, "Tax rates, tax administration and income tax evasion in Switzerland," Public Choice 88(1-2): 161-70.

Poterba, James, 1987, “Tax Evasion and Capital gains Taxation”, American Economic Review 77 (2):234-239.

Robben, H.S. et al., 1990, "Decision frame and Opportunity as Determinants of Tax Cheat: An International Experimental Study," J. Economic Psysicology 11(3): 341-64.

Seltzer, David, 1997, "Federal Income Tax Compliance Costs: A Case Study of Hewlett-Packard Company," National Tax Journal, L (3): 487-493.

Silvani, Carlos and John Brondolo, 1993, "Analysis of VAT Compliance," International Monetary Fund, Fiscal Affairs Department, mimeo.

Slemrod, Joel and Marsha Blumenthal, 1996, "The Income Tax Compliance Cost of Big Business," Public Finance Quarterly 24(4): 411-438. 
Slemrod Joel and Shlomo Yitzhaki, 1996, "The Costs of Taxation and the Marginal Efficiency Cost of Funds", IMF Staff Papers 43(1): 172-198.

Tanzi, Vito and Parthasarathi Shome, 1993, “A primer on tax evasion”, IMF Staff Papers 40(4): 807- 828.

Thurman, Quint C., 1991, “Taxpayer noncompliance and general prevention”, Public Finance XXXXVI(2): 289-298.

Thurman, Quint C., Craig St. John and Lisa R. Riggs, 1984, "Neutralization and Tax Evasion: How effective would a moral appeal be in improving compliance to tax laws?", Law and Policy 6: $309-27$.

Wallschutzky, I. G., 1984, “Possibly Causes of Tax Evasion” J. Economic Psychology 5: 371- 84. 